\title{
KAJIAN KONDISI KESEHATAN PADANG LAMUN DI PERAIRAN MOKUPA KECAMATAN TOMBARIRI KABUPATEN MINAHASA
}

\author{
(The Health Conditions Analysis of Mokupa Waters Seagrass Bed of Tombariri Sub- \\ District Minahasa Regency)
}

\section{Marthen Bongga ${ }^{1}$, Calvyn F.A. Sondak ${ }^{2}$, Deslie R.H. Kumampung ${ }^{2}$, Kakaskasen A. Roeroe $^{1}$, Sandra Olivia Tilaar ${ }^{1}$, Joudy R.R. Sangari ${ }^{3}$}

1. Mahasiswa Program Studi IImu Kelautan, FPIK, UNSRAT Manado

2. Staf Pengajar Program Studi IImu Kelautan, FPIK, UNSRAT Manado

3. Staf Pengajar Program Studi Manajemen Sumberdaya Perairan, FPIK UNSRAT Manado

Penulis korespondensi: Marthen Bongga; Marthenbongga@yahoo.com

\begin{abstract}
Seagrass ecosystems services in the coastal waters are included as primary producers, nutrient recycler, bottom stabilizers, sediment traps, and erosion barriers. Gleaning fisheries in seagrass bed in Mokupa waters could cause damage on seagrass, that can be marked by changes in seagrass cover. The purposes of this study were to identify the types of seagrasses and to determine the health condition of seagrass bed ecosystem in Mokupa waters. The research method used in this study is quadrat transect method. Data collection was carried out by laid three transects $(100 \mathrm{~m})$ with distance between each transect was $50 \mathrm{~m}$. A square frame $\left(50 \times 50 \mathrm{~cm}^{2}\right)$ which is divided into 4 squares is placed on the right side of the transect, with $10 \mathrm{~m}$ distance between frame. This study found four types of seagrasses, namely Enhalus acoroides, Thalassia hemprichii, Halodule pinifolia and Halophila ovalis. E. acoroides have the highest percentage cover (16.19\%) followed by T. hemprichii $(6.91 \%), H$. pinifolia $(4.50 \%)$ and $H$. ovalis $(1.56 \%)$ respectively. Seagrass cover in the study area is considered medium (26-50\%) while the health condition was poor (29.25\%).
\end{abstract}

Keywords: Mokupa, Seagrass, Health Condition, Cover

\section{ABSTRAK}

Ekosistem lamun di daerah pesisir mempunyai produktivitas biologis yang tinggi, memiliki fungsi sebagai produsen primer, pendaur zat hara, stabilisator dasar perairan, perangkap sedimen, serta penahan erosi. Kegiatan eksploitasi biota pada area padang lamun di Perairan Mokupa dapat mengakibatkan kerusakan lamun, di mana kerusakan dari lamun tersebut dapat ditandai dengan berubahnya tutupan lamun. Tujuan penelitian ini adalah untuk mengidentifikasi jenis lamun dan mengetahui kondisi kesehatan ekosistem padang lamun yang terdapat di perairan Mokupa. Metode penelitian yang digunakan dalam penelitian ini adalah transek kuadratHasil penelitian di perairan Mokupa ditemukan 4 jenis lamun yaitu Enhalus acoroides, Thalassia hemprichii, Halodule pinifolia dan Halophila ovalis. Enhalus acoroides dengan persentase tutupan jenis tertinggi 16,19\%, jenis lamun Thalassia hemprichii 6,91\%, jenis Halodule pinifolia 4,50\% dan untuk jenis lamun yang memiliki persentase tutupan terendah adalah Halophila ovalis $1,56 \%$. Status kesehatan padang lamun yang terdapat di lokasi penelitian termasuk dalam kategori miskin dengan penutupan lamun $29,25 \%$. Jika dilihat berdasarkan kriteria kategori tutupan lamun maka tutupan lamun yang terdapat di lokasi penelitian dapat di kategorikan sedang dengan penutupan (26$50 \%)$.

Kata kunci: Mokupa, Lamun, Kondisi Kesehatan, Tutupan 


\section{PENDAHULUAN}

Lamun adalah tumbuhan berbunga (Angiospermae) yang hidup terendam dalam kolom air dan berkembang dengan baik di perairan laut dangkal dan estuari. Tumbuhan lamun terdiri dari daun dan seludang, batang menjalar yang biasanya disebut rimpang (rhizoma), dan akar yang tumbuh pada bagian rimpang (Rahmawati $d k k, \quad 2017)$. Padang lamun adalah ekosistem yang sangat penting karena memiliki peranan penunjang di bidang perikanan atau kaitannya dengan ekosistem pesisir lainnya seperti terumbu karang dan mangrove.

Keberadaan ekosistem lamun di wilayah pesisir secara ekologis memberikan kontribusi yang cukup besar terutama berperan penting sebagai penyumbang nutrisi bagi kesuburan lingkungan perairan pesisir dan laut. Ekosistem lamun di daerah pesisir mempunyai produktivitas biologis yang tinggi, memiliki fungsi sebagai produsen primer, pendaur zat hara, stabilisator dasar perairan, perangkap sedimen, serta penahan erosi (Dwintasari, 2009 dalam Nainggolan,2011).

Ekosistem lamun di Indonesia biasanya terletak di antara ekosistem mangrove dan terumbu karang, atau terletak di dekat pantai berpasir dan hutan pantai. Kedalaman air dan pengaruh pasang surut, serta struktur substrat mempengaruhi zonasi sebaran jenis-jenis lamun dan bentuk pertumbuhannya. Jenis lamun yang sama dapat tumbuh pada habitat yang berbeda dengan menunjukkan bentuk pertumbuhan yang berbeda dan kelompok-kelompok jenis lamun membentuk zonasi tegakan yang jelas, baik murni ataupun asosiasi dari beberapa jenis (Kiswara, 1997). Selain dari itu faktor lingkungan yang lainnya juga ikut mempengaruhi pertumbuhan dan sebaran lamun seperti faktor fisik, kimia dan biologi. Padang lamun merupakan habitat dari hewan laut dan bertindak sebagai penyeimbanng substrat.

Saat ini padang lamun kondisinya terancam baik secara alami maupun oleh aktifitas manusia, contoh kecil adalah hilangnya padang lamun karena akibat aktifitas manusia yang ada di daerah pesisir seperti pengerukan, jangkar, eutrofikasi, budidaya perikanan, pengumpulan biota laut dan pembangunan pada daerah pesisir. Hilangnya padang lamun ini diduga akan terus meningkat akibat tekanan pertumbuhan penduduk di daerah pesisir (Kiswara, 2009).

Rusaknya padang lamun cukup mengkhawatirkan sehingga perlu dilakukan pengamatan untuk kondisi kesehatan padang lamun secara berkelanjutan yang merupakan salah satu upaya untuk mengurangi terjadinya kerusakan padang lamun serta mengembalikan fungsi padang lamun sebagai asuhan untuk beberapa jenis biota perairan. Untuk itu diperlukan penilaian tutupan lamun dan distribusi spasial spesies lamun untuk memastikan manfaat padang lamun tetap ada (Adi $d k k$, 2019). Penelitian ini dilakukan untuk memberikan informasi mengenai kondisi terkini padang lamun di perairan Mokupa.

\section{METODE PENELITIAN}

\section{Waktu dan Tempat}

Penelitian ini dilaksanakan pada bulan Juni 2021. Lokasi penelitian bertempat di Perairan Mokupa, Kecamatan Tombariri, Kabupaten Minahasa dengan titik koordinat $1^{\circ} 24^{\prime} 58.68$ "N, $124^{\circ} 42^{\prime} 24.76$ "E (Gambar 1).

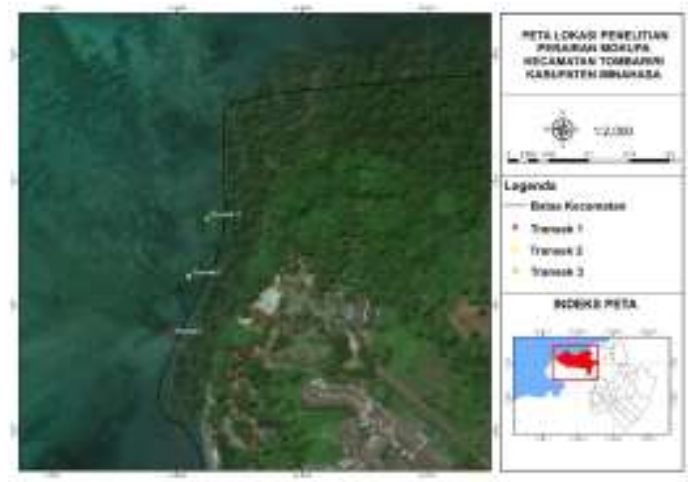

Gambar 1. Peta Lokasi Penelitian 


\section{Prosedur penelitian}

Metode yang digunakan di dalam penelitian ini adalah transek kuadrat (Rahmawati dkk, 2017). Metode transek kuadrat terdiri dari transek dan frame berbentuk kuadrat. Pengambilan data dilakukan dengan penentuan tiga transek dengan panjang masing-masing transek adalah $100 \mathrm{~m}$ kemudian ditentukan jarak antara transek satu dengan transek lainnya $50 \mathrm{~m}$ sehingga total luasannya $100 \times 100$ $\mathrm{m}^{2}$. Jarak antara kuadrat adalah $10 \mathrm{~m}$ sehingga total kuadrat yang terdapat dalam satu transek adalah 11 kuadrat. Setelah ditentukan titik koordinat lokasi pengambilan data, langkah awal adalah penarikan transek yang berukuran $100 \mathrm{~m}$ dari arah laut dan, selanjutnnya dilakukan peletakan kuadrat yang berukuran $50 \times 50 \mathrm{~cm}^{2}$ mulai di titik $0 \mathrm{~m}$, di sebelah kanan transek. Frame kuadrat dibagi atas 4 kotak untuk menentukan nilai persentase tutupan lamun.

Table 1. Penilaian Penutupan Lamun dalam Kotak Kecil Penyusun Kuadrat $50 \times 50 \mathrm{~cm}^{2}$.

\begin{tabular}{lc}
\hline \multicolumn{1}{c}{ Kategori } & $\begin{array}{c}\text { Nilai } \\
\text { Penutupan } \\
\text { Lamun }\end{array}$ \\
\hline Tutupan Penuh & 100 \\
$\begin{array}{l}\text { Tutupan } 3 / 4 \\
\text { kotak kecil }\end{array}$ & 75 \\
$\begin{array}{l}\text { Tutupan } 1 / 2 \\
\text { kotak kecil } \\
\text { Tutupan } 1 / 4 \\
\text { kotak kecil }\end{array}$ & 50 \\
Kosong & 25 \\
\hline
\end{tabular}

\section{Pengukuran parameter lingkungan}

Pengukuran parameter lingkungan dilakukan setelah pengambilan data lamun, pengukuran parameter yang pertama adalah suhu dengan menggunakan thermometer, Pengukuran parameter ke dua yaitu salinitas diukur dengan alat refraktometer, pengukuran ke tiga yaitu Derajat keasaman $(\mathrm{pH})$ diukur dengan menggunakan kertas lakmus. Selain melakukan pengukuran kualitas air, juga dilakukan pengamatan seara visual terhadap substrat yang terdapat dari setiap titik sampling.

\section{Analisis data}

\section{Menghitung penutupan lamun dalam} satu kuadrat

Menurut Rahmawati dkk, (2017) cara menghitung tutupan lamun dalam setiap kuadrat adalah menjumlah nilai penutupan lamun pada setiap kotak kecil dalam kuadrat yang membaginya dengan jumlah kotak kecil, yaitu 4 kotak. Untuk menghitung persentase tutupan lamun dalam kotak kecil dapat dihitung dengan rumus (Rahmawati $d k k, 2017)$.

Persamaan 1:

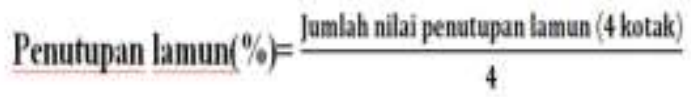

\section{Menghitung rata-rata penutupan lamun per transek/stasiun}

Untuk menghitung penutupan lamun per transek atau stasiun dapat dilakukan dengan menjumlah penutupan lamun setiap kuadran yaitu hasil dari persamaan 1, pada seluruh transek dalam satu stasiun. Kemudian hasil penjumlahan dibagi dengan jumlah kuadran dalam transek atau stasiun tersebut. Untuk menghitung nilai rata-rata penutupan lamun per transek atau stasiun dapat menggunakan rumus (Rahmawati $d k k, 2017)$.

Persamaan 2:

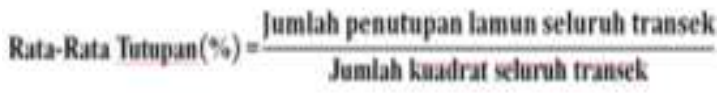

\section{Menghitung penutupan lamun per jenis pada satu transek/stasiun}

Penutupan lamun per jenis ini dihitung untuk mengetahui jenis lamun yang paling dominan pada suatu lokasi berdasarkan 
persentase penutupannya. Cara menghitung penutupan lamun per jenis lamun dalam satu stasiun adalah menjumlah nilai persentase penutupan setiap jenis lamun pada setiap kuadrat seluruh transek dan membaginya dengan jumlah kuadrat pada stasiun tersebut. Cara menghitung nila penutupan lamun per jenis pada satu transek atau stasiun dapat menggunakan persamaan (Rahmawati $d k k$, 2017).

Persamaan 3:

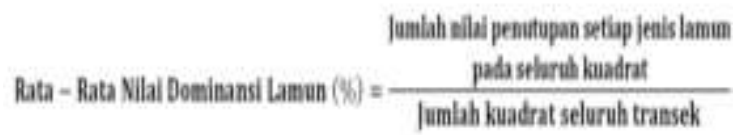

\section{Menghitung rata-rata penutupan lamun per lokasi}

Untuk menghitung rata-rata penutupan lamun perlokasi/pulau adalah menjumlah rata-rata penutupan lamun setiap stasiun yaitu hasil dari persamaaan 2, pada suatu lokasi atau pulau. Kemudian hasilnya dibagi dengan jumlah stasiun yang berada pada setiap lokasi.

Persamaan 4:

\section{Penentuan kondis kesehatan padang lamun}

Penentuan status kesehatan padang lamun telah dikategorikan dalam Keputusan Menteri Kependudukan dan Lingkungan Hidup nomor 200 Tahun 2004. Dalam keputusan tersebut kondisi padang lamun dibagi menjadi 3 kategori, yaitu sehat,

kurang sehat, dan miskin. Kondisi kesahatan lamun dapat dikategorikan dalam kategori sehat jika penutupan lamun di suatu daerah $>60 \%$, kurang sehat jika 30 $59,9 \%$ dan miskin jika penutupan antara 0 $29,9 \%$ (Tabel 2).

Tabel 2. Penentuan status padang lamun

\begin{tabular}{lll}
\hline & KONDISI & PENUTUPAN \\
\hline BAIK & KAYA/SEHAT & $>60 \%$ \\
RUSAK & KURANG & $30-59,9 \%$ \\
& KAYA/ & \\
& KURANG & \\
& SEHAT & \\
& MISKIN & $<29,9 \%$ \\
\hline Sumber. & KEPMEN KLH No 200/2004
\end{tabular}

\section{HASIL DAN PEMBAHASAN}

Desa Mokupa merupakan salah satu wilayah yang ada di kecamatan tombariri yang termasuk dalam Kabupaten Minahasa, Keadaaan desa mokupa memiliki luas 06,00 $\mathrm{km}^{2}$ dan terletak pada ketinggian 5-750 meter dari permukaan laut dengan Curah Hujan $975 \mathrm{~mm}$ - $1.282 \mathrm{~mm} /$ tahun. Kemiringan tanah rata-rata $5-10^{\circ}$. Keadaan iklim wilayah berdasarkan klasifikasi terdiri dari dua musim dengan suhu rata-rata adalah $20^{\circ} \mathrm{C}-30^{\circ} \mathrm{C}$, dengan suhu maksimum berkisar $30^{\circ} \mathrm{C}$ (Pemerintah Kabupaten Minahasa, 2018).

\section{Jenis Lamun Yang ditemukan}

Jenis lamun yang ditemukan pada 3 transek penelitian di Perairan Mokupa yang berada tepat di perairan Lotus Resort ada 4 jenis yaitu:

\section{Enhalus acoroides}

Jenis lamun yang paling banyak dijumpai di lokasi penelitian adalah jenis lamun Enhalus acoroides. Pengamatan di lapangan menunjukkan bahwa lamun ini tumbuh pada substrat pasir dan pasir berlumpur. Jenis lamun ini diketahui 
morfologinya memiliki struktur akar serabut, daun yang panjang dan memiliki permukaan yang agak kasar. E. acoroides memiliki sebaran yang cukup luas di Indonesia, menurut data Hermawan, dkk (2017) dari 423 lokasi pemantauan padang lamun di seluruh Indonesia, diketahui bahwa $E$. acoroides dapat dijumpai di 357 lokasi. Menurut penelitan yang dilakukan Zachawerus, dkk (2015) menemukan bahwa $E$. acoroides teridentifikasi di perairan pantai desa Mokupa. Kamarrudin, dkk (2016) juga menemukan E. acoroides merupakan jenis lamun yang paling banyak dijumpai di Pulau Bangka Kecamatan Likupang.

\section{Thallassia hemprichii}

Pengamatan dilapangan saat pengam bilan data, $T$. hemprichii umumnya tumbuh pada substrat pasir berlumpur. Menurut Hermawan dkk (2007) T. hemprichii dapat tumbuh di substrat pasir berlumpur dan pecahan karang dari daerah batas pasang tetinggi sampai ke surut rendah dan kadang-kadang muncul ke atas permukaan air selama surut terendah.

Jenis lamun $T$. hemprichii memiliki rhizoma beruas-ruas dan tebal dan daun yang agak melebar namun pendek, pada helaian

daun memiliki garis/bercak coklat. Hermawa n dkk (2017) mengemukakan bahwa jenis lamun yang paling banyak di temukan di Indonesia adalah T. hemprichii dari 423 lokasi. Patty dan Rifai (2013) menemukan bahwa $T$. hemprichii hidup pada substrat pasir berlumpur dan puing karang mati/coral di perairan Pulau Mantehage. Menurut penelitian yang dilakukan Rustam, $d k k$ (2016) dan Bengkal, dkk (2019) jenis lamun $T$. hemprichii juga teridentifikasi di Pulau Lembeh dan perairan desa Tongkeina.

\section{Halodule pinifolia}

Halodule pinifolia memiliki ujung daun yang agak membulat dan memiliki satu urat daun tengah jelas, jenis lamun ini memliki rhizoma halus dengan bekas daun yang jelas menghitam.

Pengamatan dilapangan menunjukan bahwa lamun jenis $H$. pinifolia tumbuh pada substrat pasir dan pasir berlumpur dan kadang-kadang lamun ini dijumpai tumbuh di selah-selah jenis lamun yang lain. Hal ini sesuai dengan Hutomo (1997) menyatakan bahwa $H$. pinifolia umumnya dijumpai pada daerah intertidal dan biasanya tumbuh pada substrat berpasir atau berlumpur. Data dari Hermawan dkk (2017) menunjukkan bahwa dari 423 lokasi jenis lamun $H$. pinifolia dapat ditemukan pada 85 lokasi. Menurut penelitian yang dilakukan Kamaruddin, $d k k$ ((2015) menemukan bahwa jenis lamun $H$. pinifolia teridentifikasi di Pulau Bangka Kecematan Likupang.

\section{Halophila ovalis}

Bentuk daun dari jenis lamun ini berbentuk oval berpasangan dengan tangkai pada setiap ruas yang terdapat pada rimpang, jenis lamun Halophila ovalis memiliki tulang daun lebih dari 8 dan permukan daun tidak berambut.

Pengamatan dilapangan menunjukan bahwa jenis lamun ini dapat tumbuh pada substrat pasir dan pasir berlumpur. Rustam, dkk (2016) menemukan bahwa $H$. ovalis tumbuh pada substrat pasir yang terdapat di Pulau Lembeh. Wagey dan Sake (2013) menemukan bahwa jenis lamun $H$. ovalis teridentifikasi di perairan Kelurahan Tongkeina. Patty dan Rifai (2013) juga menemukan bahwa $H$. ovalis hidup pada substrat pasir berlumpur dan puing karang mati/coral di perairan Pulau Mantehage.

\section{Parameter Kualiatas Perairan}

Pengukuran parameter perairan (suhu, salinitas, $\mathrm{pH}$ ) dan jenis substrat di lokasi penelitian dapat dilihat pada tabel 3 di bawah ini. 
Tabel 3. Hasil Pengukuran Parameter Kualitas Perairan.

\begin{tabular}{|c|c|c|}
\hline Parameter & Satuan & Nilai \\
\hline Suhu & ${ }^{\circ} \mathrm{C}$ & 28 \\
\hline Salinitas & Ppt & 31 \\
\hline $\mathrm{pH}$ & $\mathrm{pH}$ & 7 \\
\hline Substrat & - & $\begin{array}{l}\text { Pasir dan Pasir } \\
\text { Berlumpur }\end{array}$ \\
\hline
\end{tabular}

parameter kualitas perairan, suhu yang terdapat pada daerah perairan Mokupa selama penelitian dilaksanakan adalah $28^{\circ} \mathrm{C}$. Suhu yang diperoleh dalam pengukuran tersebut masih tergolong dalam kisaran optimum untuk pertumbuhan lamun. Menurut Nyabakken (1992), kisaran suhu optimum bagi pertumbuhan lamun mencapai $28^{\circ} \mathrm{C}-30^{\circ} \mathrm{C}$. Pengaruh suhu bagi lamun di perairan sangat besar, dimana suhu dapat mempengaruhi proses-proses fisologi seperti proses fotosintesis, pertumbuhan lamun, dan reproduksi. Proses fisiologi tesebut akan menurun tajam apabila suhu perairan berada diluar kisaran optimal tersebut (Hasanuddin, 2013).

Salinitas yang terdapat di area padang lamun adalah 31 ppt. Nilai ini adalah nilai kisaran salinitas yang termasuk dalam kategori normal untuk daerah tropis sebagai tempat pertumbuhan lamun. Dahuri (2001) mengatakan bahwa Lamun sebagian besar memiliki kisaran toleransi yang lebar terhadap salinitas yaitu antara 10-40 ppt. Lamun akan mengalami kerusakan fungsional jaringan sehingga akan mengalami kematian jika berada pada batas toleransinya. Salah satu faktor yang menyebabkan kerusakan lamun adalah meningkatnya salinitas yang diakibatkan oleh kurangnya suplai air tawar.

$\mathrm{pH}$ mewakili kekuatan keasaman atau alkalinitas sampel air dan mewakili konsentrasi ion hidrogen konsentrasi ion ini menghambat reaksi kimia yang akan terjadi. Hasil pengukuran derajat keasaman $(\mathrm{pH})$ perairan, selama penelitian berada pada kisaran 6-7. Dinyatakan tidak melebihi baku mutu air laut untuk biota laut yaitu kisaran antara 7-8,5 (KEPMEN LH NO.51 Tahun
2004). Sebagian besar vegetasi akuatik sangat sensitif terhadap perubahan $\mathrm{pH}$ dan menyukai kisaran $\mathrm{pH}$ pada rentang nilai 7 8,5. Nilai $\mathrm{pH}$ sangat mempengaruhi proses biokomiawi perairan, pada kisaran $\mathrm{pH}<$ 4.00, sebagian besar tumbuhan akuatik akan mati karena tidak dapat bertoleransi pada $\mathrm{pH}$ rendah (Effendi, 2003).

Secara visual substrat padang lamun di lokasi penelitian didominasi oleh substrat pasir dan pasir berlumpur. Jenis substrat yang diamati pada transek pertama dan kedua didominasi oleh substrat pasir sedangkan pada transek ke tiga didominasi oleh substrat pasir berlumpur. Kedalaman substrat berperan dalam menjaga stabilitas sedimen yang mencakup 2 hal yaitu pelindung tanaman dari air laut, dan sebagai tempat pengolahan atau pemasok nutrient (Hoek, 2016). Yunitha, dkk 2014 mengungkapkan bahwa keberadaan substrat memiliki peranan penting bagi pertumbuhan dan kelangsungan lamun sebagai media hidup dan sebagai pemasok nutrisi

\section{Menghitung Penutupan Lamun Dalam Satu Kuadrat}

Hasil dari penutupan lamun dalam setiap kuadrat di dalam transek di lokasi penelitian yang terdapat di perairan sekitar Desa Mokupa disajikan pada Tabel 4.

Tabel 4. Penutupan lamun dalam kuadrat

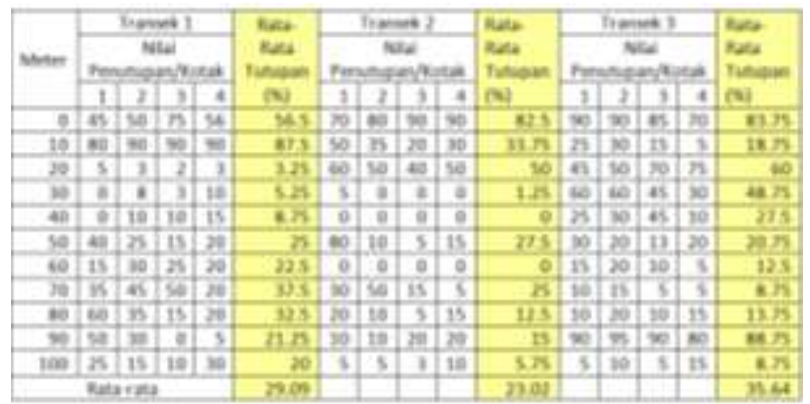


Pada transek 1 penutupan lamun tertinggi terdapat di kuadrat ke-dua atau meter ke 10 dengan rata-rata tutupan $87,5 \%$ sedangkan kategori tutupan terendah terdapat pada kotak ke 3 atau meter ke 20 dengan nilai rata-rata tutupan $3,25 \%$. Transek/lokasi 2 kategori tutupan lamun tertinggi terdapat pada kuadrat pertama atau pada titik 0 meter dengan nilai rata-rata penutupan lamun $82,5 \%$ dan untuk kategori terendah terdapat pada kuadrat ke lima dan tujuh atau pada titik 40 meter dan 60 meter dengan nilai rata-rata tutupan $0 \%$. Sedangkan tutupan lamun pada transek/lokasi ke 3 tutupan tertinggi terdapat pada kuadrat ke 10 atau pada titik 90 meter dengan nilai tutupan rata-rata $88,75 \%$ dan kategori tutupan terendah terdapat pada kuadarat ke 8 dengan nilai rata-rata tutupannya $8,75 \%$.

\section{Rata-rata penutupan lamun per transek}

Untuk menghitung penutupan lamun per transek dilakukan dengan menjumlahka $\mathrm{n}$ penutupan lamun setiap kuadrat yaitu hasil dari persamaan 1, pada seluruh transek

kemudian hasil penjumlahan hasil penjumla han dibagi dengan jumlah kuadrat dalam transek tersebut. Hasil yang didapat menunj ukkan bahwa pada lokasi transek 1 nilai rata-rata tutupan lamun adalah $29,09 \%$.

Berdasarkan kategori tutupan lamun Rahma wati, dkk (2017) maka tutupan lamun yang terdapat pada transek 1 dapat di kategorikan sedang dengan persentase penutupan berada antara (26-50\%), transek ke 2 memiliki nilai rata-rata tutupan 23,02\%. Berdasarkan kategori Rahmawati, dkk (2017) kategori tutupan lamun pada transek ke 2 termasuk dalam kategori jarang (0$25 \%$ ), sedangkan transek 3 memiliki nilai rata-rata tutupan lamun yang paling tinggi dari ke tiga transek yang dipasang yaitu $35,64 \%$, berdasarkan kategori Rahmawati, dkk (2017) tutupan lamun pada transek ke 3 dapat di kategorikan sedang (26-50\%).
Berdasarkan KEPMEN KLH No 200/2004 status padang lamun di transek ke 1 dan 2 dikategorikan miskin, sementara pada transek 3 termasuk dalam kategori kurang sehat. Menurut Alongi (1998) dalam Hidayat \& Widyorini (2014), beberapa faktor yang mempengaruhi keberadaan lamun di suatu perairan adalah suhu, cahaya, salinitas, kedalaman, substrat daras perairan dan pergerakan air laut. Faktor-faktor tersebut juga mempengaruhi kelimpahan dan tutupan lamun pada suatu daerah, sehingga jumlah dan kelimpahannya mungkin berbeda-beda. Suhu yang terukur dalam penelitian ini berada pada angka $28^{\circ} \mathrm{C}$ dan masih tergolong dalam kisaran optimum untuk pertumbuhan lamun. Hasil dari penutupan lamun per transek atau stasiun dapat dilihat pada Gambar 2.

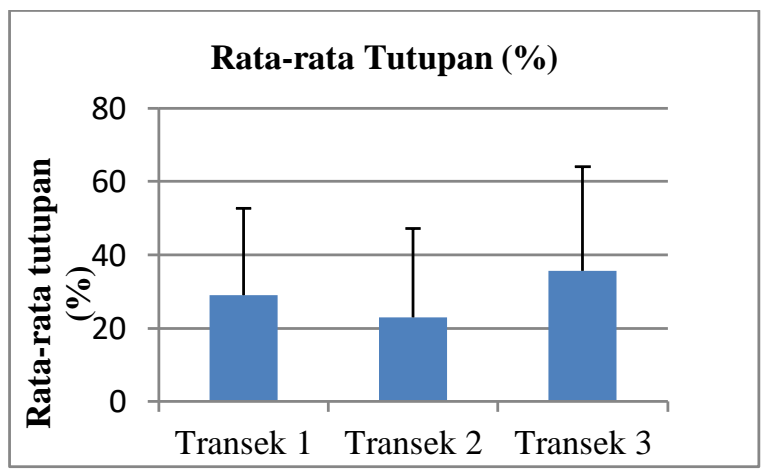

Gambar 2. Rata-Rata Penutupan Lamun Per transek/stasiun

\section{Tutupan lamun per jenis pada satu transek/stasiun}

Jenis lamun yang didapatkan pada ke tiga transek terdiri dari 4 jenis, pada transek 1 jenis Enhalus acoroides memiliki persentase tutupan 14,91\%, T. hemprichii memiliki persentase tutupan 5,73\%, $H$. pinifolia memiliki persentase $6,00 \%$, dan jenis $H$. ovalis memiliki nilai persentase yang paling rendah dari ke tiga jenis yang ada yaitu dengan nilai $2,18 \%$. Pada transek 2 jenis $E$. acoroides nilai persentasenya $14,46 \%$, T. hemprichii dengan nilai persentase $7,05 \%, H$. pinifolia dengan nilai $1.30 \%$, dan $H$. ovalis dengan nilai persentase $0,23 \%$. Pada transek 3 jenis 
lamun E. acoroides memiliki nilai persentase $19,21 \%$ dari ke tiga transek yang dipasang nilai persentase tutupan jenis lamun $E$. acoroides yang paling tinggi terdapat pada transek ke 3 , jenis lamun $T$. hemprichii memiliki nilai persentase $7,96 \%$, $H$. pinifolia dengan nilai persentase $6,21 \%$, dan jenis lamun $H$. ovalis dengan nilai persentase $2,27 \%$. Hasil dari keseluruhan penutupan lamun per jenis dapat dilihat pada Gambar 3.

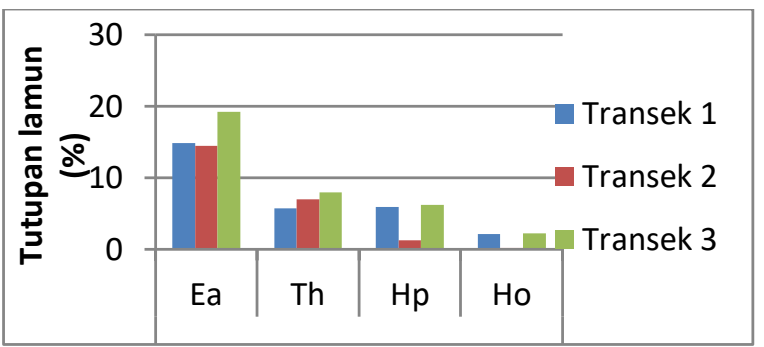

Gambar 3. Dominasi lamun Per Jenis

Keterangan Tabel dan Gambar:

\section{Ea: Enhalus acoroides}

Th: Thallasia hemprichii

Hp: Halodule pinifolia

Ho: Halophila ovalis

\section{Tutupan Lamun Per Lokasi}

Untuk menghitung penutupan lamun per lokasi adalah menjumlahkan rata-rata penutupan lamun keseluruhan transek dalam satu lokasi yaitu hasil dari persamaan 2, kemudian hasilnya dibagi dengan jumlah transek yang dipasang dalam lokasi tersebut. Dari hasil penelitian yang telah dilakukan di Perairan Mokupa, didapatkan hasil persentase rata-rata tutupan lamun pada keseluruhan transek yaitu $29.25 \%$, jika dilihat berdasarkan kriteria kategori tutupan lamun Rahmawati, dkk (2017) maka tutupan lamun yang terdapat di lokasi penelitian dapat di kategorikan sedang (26-50\%). Nilai persentase tutupan lamun yang paling tinggi terdapat pada transek 3 dengan nilai ratarata tutupan $35,64 \%$, sedangkan nilai persentase tutupan yang paling rendah terdapat di transek 2 dengan nilai rata-rata tutupan 23,02\%. Menurut Stella, dkk (2011) penutupan lamun dapat dipengaruhi oleh keadaan lingkungan seperti parameter perairan dan aktifitas manusia.

Nilai penutupan lamun tertinggi ditemukan di transek 3 , hal ini diduga karena jenis substrat yang terdapat pada transek ke 3 dimana didominasi oleh substrat pasir berlumpur dan jenis lamun yang paling banyak dijumpai adalah jenis lamun $E$. acoroides sedangkan pada transek pertama dan ke 2 didominasi oleh substrat pasir. Menurut Tomascik, dkk (1997) dalam Hasanuddin (2013) E. acoroides merupakan spesies yang paling umum ditemukan di sedimen halus hingga lumpur tetapi pada sedimen sedang hingga kasar ia tetap dapat tumbuh sebab akarakarnya panjang dan kuat sehingga mampu menyerap makanan dengan baik dan dapat berdiri dengan kokoh. Tingginya lamun jenis E. acoroides dominan hidup pada substrat pasir berlumpur dan pasir bercampur pecahan karang yang telah mati. (Dewi, 2012). Hasil dari keseluruhan rata-rata tutupan lamun dapat dilihat pada Gambar 4.

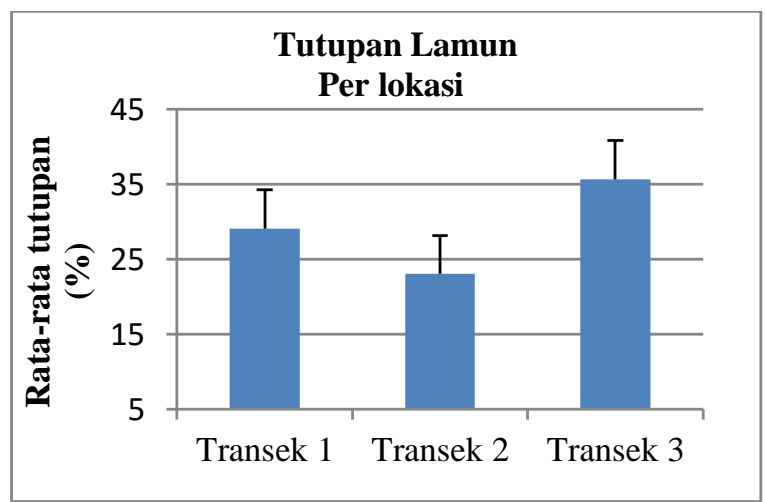

Gambar 4. Tutupan lamun per lokasi dan standar deviasinya

\section{Penentuan Kondisi Kesehatan Padang Lamun}

Penentuan status padang lamun telah dikategorikan dalam Keputusan Menteri Kependudukan dan Lingkungan Hidup 
nomor 200 Tahun 2004. Kondisi kesehatan lamun dapat dikategorikan dalam kategori sehat jika penutupan lamun di suatu daerah $>60 \%$, kurang sehat jika 30-59,9\% dan miskin jika penutupan antara 0-29,9\%.

Dari data pengkategorian tersebut dapat di simpulkan bahwa kondisi kesehatan padang lamun yang terdapat di lokasi penelitian dikategorikan dalam kondisi miskin dengan nilai rata-rata penutupan lamun 29,25\%. Rendahnya angka penutupan lamun yang terdapat di lokasi penelitian diduga karena tingginya aktivitas masyerakat di daerah tersebut seperti kegiatan memanen hewan laut selama air surut. Kegiatan memanen hewan laut pada saat air surut dapat mengakibatkan terjadinya kerusakan lamun karena secara tidak sengaja masyerakat akan menginjak lamun sehingga dapat menghambat pertumbuhan lamun. Selain dari itu aktivitas manusia yang berlebihan di lokasi ini dapat mengakibatkan naiknya sedimen pada badan air yang akan berakibat pada tingginya kekeruhan perairan, sehingga berpotensi mengurangi penetrasi cahaya. Hal ini dapat menimbulkan gangguan terhadap produktivitas primer ekosistem padang lamun karena lamun membutuhkan intensitas cahaya yang tinggi untuk berfotosintesis (Rochmady, 2010). Menurut Sjafrie, dkk (2018), permasalahan utama yang mempengaruhi ekosistem lamun di seluruh dunia adalah kerusakan yang disebabkan oleh aktivitas manusia dan kurangnnya kesadaran tentang lamun rendah pada level masyarakat, manager, aparat pemerintah, sehingga sulit untuk membuat aturan baru dan mentaati aturan lama.

\section{KESIMPULAN DAN SARAN}

\section{Kesimpulan}

Kesimpulan yang didapatkan dalam penelitian ini yaitu:

1. Jenis lamun yang di temukan di perairan Mokupa teridentifikasi sebanyak 4 spesies yaitu E. acoroides, T. hemprichii, $H$.pinifolia, dan $H$. ovalis.

2. Status kesehatan padang lamun yang terdapat di lokasi penelitian termasuk dalam kategori miskin dengan penutupan lamun 29,25\%. Tutupan lamun yang terdapat di lokasi penelitian dapat di kategorikan sedang dengan penutupan (26-50\%).

\section{DAFTAR PUSTAKA}

Adi, W., Nugraha, A.H., Dasmasela, Y,H., Ramli, A., Sondak, C.F.A., Sjafrie, N.D.M. 2019. Struktur komunitas lamun di Malang Rapat, Bintan. Jurnal Enggano 4(2): 148-159

Bengkal, K.P., Manembu, I.S., Sondak, C.F.A., Wagey, B. Th., Schaduw, J.N.W. dan Lumingas, L.J.L. 2019. Identifikasi keanekaragaman lamun dan ekinodermata dalam upaya konservasi. Jurnal Pesisir dan Laut Tropis 1(1): 29-39

Dahuri, R. 2001. Pengelolaan sumber daya wilayah pesisir dan lautan secara terpadu. PT. Pradnya Paramita. Jakarta.

Dewi, R. F., 2012. Pengelolaan Ekosistem Lamun Kawasan Wisata Pantai Sanur Kota Denpasar Provinsi Bali. [Skripsi]. Institut Pertanian Bogor.

Effendi, H. 2003. Telaan Kualitas Air: Bagi Pengelolaan Sumber Daya dan Lingkungan Perairan. Penerbit Kanisus. Yogyakarta 257 hal.

Hasanuddin, R. (2013). Hubungan Antara Kerapatan Dan Morfometrik Lamun Enhalus Acoroides Dengan Substrat Dan Nutrien Di Pulau Sarappo Lompo Kab. Pangkep. Skripsi. Jurusan IImu Kelautan, Fakultas IImu Kelautan Dan Perikanan Universitas Hasanuddin. Makassar. 
Hermawan, U.E, Sjafrie, N.D.M., Supriyadi, I.H., Suyarso., Iswari, M.Y., Agrraini, K. dan Rahmat. (2017). Status Padang Lamun Indonesia 2017. Jakarta: Puslit Oseanografi-LIPI Jakarta 23 hal.

Hidayat, M., \& Widyorini, N. (2014). Analisis laju sedimentasi di daerah padang lamun dengan tingkat kerapatan berbeda di Pulau Panjang, Jepara. Management of Aquatic Resources Journal (MAQUARES), 3(3), 73-79.

Hoek, F., Razak, A., Hamid, H., Muhfizar, M., Suruwaky, A. M., Ulat, M. A., ... \& Arfah, A. (2016). Struktur Komunitas Lamun di Perairan Distrik Salawati Utara Kabupaten Raja Ampat. Jurnal Airaha, 5(1), 087-095.

Hutomo, M. (1997). Padang lamun Indonesia: salah satu ekosistem laut dangkal yang belum banyak dikenal. Jurnal Puslitbang Oseanologi-LIPI, 35.

Kamarrudin, Z. S., Rondonuwu, S. B., dan Maabuat, P. V. (2016). Keragaman Lamun (Seagrass) di Pesisir Desa Lihunu Pulau Bangka Kecamatan Likupang Kabupaten Minahasa Utara, Sulawesi Utara. Jurnal MIPA, 5(1), 20-24.

Kementerian Negara Lingkungan Hidup. (2004). Keputusan menteri negara lingkungan hidup no: 51 tahun 2004 tentang baku mutu air laut. Deputi Menteri Lingkungan Hidup: Bidang Kebijakan dan Kelembagaan LH Jakarta.

Keputusan Menteri Negara Lingkungan Hidup. (2004). Keputusan Menteri Negara dan Lingkungan Hidup No. 200 tahun 2004 tentang, Kriteria Baku Kerusakan dan Pedoman Penentuan Status Padang Lamun. 16 hal.
Kiswara W, Ulumuddin YI. 2009. Peran Vegetasi Pantai dalam Siklus Karbon Global: Mangrove dan Lamun sebagai Rosot Karbon. Workshop Ocean and Climate Change. Laut sebagai Pengendali Perubahan Iklim: Peran Laut Indonesia dalam Mereduksi Percepatan Proses Pemanasan Global. Bogor 4 Agustus 2009.

Kiswara, W. (1997) Struktur Komunitas Padang Lamun Perairan Indonesia. Inventarisasi dan Evaluasi Potensi Laut-Pesisir II, Jakarta: P3O LIPI. Hal. 54-61.

Nainggolan, P. (2011). Distribusi spasial dan pengelolaan lamun (seagrass) di teluk bakau, kepulauan Riau. Skripsi, IPB. Bogor

Nybakken JW., 1992. Biologi Laut Suatu Pendekatan Ekologis. Penerbit PT. Gramedia Jakarta.

Patty, S. I., dan Rifai, H. (2013). Struktur komunitas padang lamun di perairan Pulau Mantehage, Sulawesi Utara. Jurnal IImiah Platax, 1:(4): 177, 186.

Pemerintah Kabupaten Minahasa. (25 Nov. 2018). Diakses tanggal 10 juli. 2021, dari

https://minahasa.go.id/detailpost/tomb ariri

Rahmawati, S. Irawan, Andri. Indarto. Supriyadi, Happy. Azkab, Muhammad Husni. 2017. Panduan Pemantauan Penilaian Kondisi Padang Lamun. Jakarta: COREMAP CTI LIPI

Rochmady, R. 2010. Rehabilitasi ekosistem padang lamun. Program Pascasarjana, Universitas Hasanuddin. Makassar. 25 hal.

Rustam, A., Kepel, T. L., Kusumaningtyas, M. A., Ati, R. N. A., Daulat, A., Suryono, D. D., ... \& Hutahaean, A. A. 
(2016). Ekosistem lamun sebagai bioindikator lingkungan di P. Lembeh, Bitung,

Sulawesi Utara. Jurnal Biologi Indone sia, 11(2).

Sjafrie, N.D.M., Hernawan, U.E., Prayudha, B., Supriyadi, I.H., Iswari, M.Y., Rahmat, K. Anggraini, Rahmawati, S., dan Suyarso. 2018. Status padang lamun Indonesia 2018. Ver. 02. Coremap-CTI - Pusat Penelitian Oseanografi LIPI. Jakarta.

Stella, AL, V, Khaerunisa, S., dan Madaul, U. K. (2011). Kerapatan dan Penutupan Jenis Lamun di Gugusan Pulau Pari, Kepulauan Seribu, Jakarta. 13 hal.

Wagey, B. T., dan Sake, W. (2013). Variasi Morfometrik Beberapa Jenis Lamun Di Perairan Kelurahan Tongkeina Kecamatan Bunaken. Jurnal Pesisir dan Laut Tropis, 1(3), 36-44.

Yunitha, A., Wardiatno, Y., \& Yulianda, F. (2014). Diameter substrat dan jenis lamun di pesisir Bahoi Minahasa Utara: sebuah analisis korelasi. Jurnal IImu Pertanian Indonesia, 19(3), 130135.

Zachawerus, F. H., Kambey, A. D., dan Mantiri, R. O. (2015). Structure Community of Seagrass (Lamun) In The Village Beach Of Mokupa Tombariri Subdistrict, Minahasa District North Sulawesi. Jurnal IImiah PLATAX, 3(1), 16-21. 